\title{
Antibacterial activity of Oscillatoria ethanolic extract and extracted phenolic compounds
}

\author{
Mira A. Al-Katib ${ }^{1}$ and Ayman S. Amin ${ }^{2}$ \\ \{mirausama@uomosul.edu.iq ${ }^{1}$, mirausama@yahoo.com ${ }^{2}$ \} \\ 1,2 Department of Biology, Education of Pure Science College, Mosul University, \\ Mosul, Iraq
}

\begin{abstract}
The aim of this study is to investigate the antibacterial effect of cyanobacterium via detection of phenolic compounds with antibacterial activity, Recently, a new search for friendly to the environment alternatives to antibiotics has been explored, so there is a trend to use cyanobacteria, which are one of type of microalgae as a source for obtaining compounds that have an anti-bacterial effect. Cyanobacteria is an important source of many bioactive compounds, such as phenols, alkaloids, terpenes, fatty acids, and many other bioactive compounds. Ethanolic extract of Oscillatoria had no effect towards Gram positive Staphylococcus aureus, Bacillus subtilis) and negative bacteria (Pseudomonas aeruginosa, Escherichia coli), while the phenolic compound isolated from that ethanolic extract showed a clear effect on the above-mentioned bacteria. The Gram-positive bacteria are more sensitive to phenols compared with a negative one, according to the results of inhibition zones diameters for each treatment. The highest inhibition $(20,19 \mathrm{~mm})$ for Gram positive bacteria and $(10,16 \mathrm{~mm})$ for Gram negative. Many phenols have been diagnosed through the use of HPLC technology such as Quercetin (11.8\%), Apigenin (11.5\%), Rutin (44.4\%), Kaempferol (5.2\%) and Luteolin (9.4\%).
\end{abstract}

Keywords: Cyanobacteria, Phenols, Antimicrobial activity

\section{Introduction}

The development of pathogenic bacteria for many mechanisms of continuous defense against the drugs requires research about other materials that are cheaper and natural that are friendly to the environment. Of these materials, are bioactive compounds that are represented in secondary metabolites of microalgae (cyanobacteria is an example).

Algae are a group of organisms that have recently become popular in researches and different industrial fields because of their direct and indirect relationships in different areas of individual life, as well as they possess an important role in respect to the bio-based economy because of its unique properties that distinguish it from other organisms. The algae can be grown efficiently in areas not suitable for cultivation and it is a source of many products including biodiesel [1]. Microscopic algae in particular have tremendous potential if it used in the field of biotechnology which is very important as a biological system or bioreactors for the production of several valuable chemicals. It is believed that the best results are obtained using algae by providing appropriate conditions in photobioreactors [2]. The algae are photosynthetic organisms that have the ability to produce organic carbon during photosynthesis, and their individuals vary in size, cellular composition, and biological characteristics [3].

Algae are commonly classified into microalgae and macroalgae depending on their cellular organization and microalgae have the potential to produce several bioproducts [4]. Microalgae 
are unicellular and multicellular microorganisms that produce important industrial compounds, and it includes prokaryotic microalgae (cyanobacteria) and eukaryotic microalgae which include Bacillariophyta (diatoms), Chlorophyta (green algae) and Rhodophyta (red algae). Microalgae with simple growth requirements can be the best resource for promising environmentally friendly alternatives such as pharmaceutics, nutraceuticals [5].

Cyanobacteria, also known as Blue Green Algae (BGA) are a class of Gram negative bacteria that are very unique due to the oxygenic nature of their photosynthesis that is similar to higher plants [6]. However, microalgae could be an alternative resource of natural antioxidants as they are much more diverse than other sources. Like plants, antioxidants include either phenolic compounds or pigments (Carotenoids) [7].

The ability of algae to produce antimicrobial substances could be used not as a defense agent against pathogens but also as pharmaceutical bioactive natural compounds. Phenolic compounds, cause an injury of the membrane functions has been proposed as a mechanism of action [8]. phenolic compounds are important antioxidants and polyphenols act as antioxidants through single electron transfer and hydrogen atom transfer. Microalgae are also able to produce more complex phenolic compounds, so research of phenolic compounds in microalgae is required, especially as they may contain novel phenolic compounds. There are only a few published studies interested in that subject for identification and quantification of phenolic composition in microalgae species [7]. Therefore, we need more research in detecting kinds of phenolic compounds in different species of microalgae with the study of the effect of various conditions on its production from these organisms. The verify of manner for production is effect also a phenolic content and detection of its compounds in microalgae extract, thus the results of antimicrobial activity of that extracts differ from research to another.

Cyanobacteria classification depends on their ability to perform photosynthesis because they contain Chlorophyll. It is noted since ancient periods that there are several names including Cyanophyceae, Schizophceae, and Myxoohceae, then blue-green algae and also named Chloroxybacteria described as the oldest oxygen-producing photosynthetic organisms [9]. It was indicated that they are true Gram negative bacteria [4],[6]. The Oscillatoria sp. Cyanobacterium belongs to the Oscillatoriaceae family and it is a dark bluish-green alga as a non-branched cylindrical thread common in shallow water trenches and ponds. The thread is considered a colony and all cells are the same except for the terminal cell is often convex and the thread is undifferentiated to the base and apex and some cells are dead and empty that as viewed at areas in some threads. The taxonomic position of Oscillatoria is:

Division: Cyanophyta

Class: Cyanophyceae

Tribe: Hormogoneae

Order: Oscillatoriales

Family: Oscillatoriaceae [10].

There is also another classification of demand as follows: Order is Nostocales [11]. Phenolic compounds consist of an aromatic ring that is associated with a group of one or more hydroxylates, whose name is due to the simplest of these compounds is phenyl $\mathrm{C}_{6} \mathrm{H}_{5} \mathrm{OH}$. Phenols are white crystals in the state of solid and are colorless in the state of liquidity and have a smell similar to that of detergents and sterilizers [12]. Phenols are secondary metabolites that have multiple uses, low molecular weights, and inhibitory effects for bacteria and fungi [13],[14]. Natural phenolic substances enter the composition of thousands of compounds known as flavonoids that represent the largest group in addition to simple-ring phenols, the phenylpropionate, and phenolic cations, which are present in large numbers of plants, the distinguished phenolic substances are water-soluble substances, and their solubility increases 
with the increasing number of hydroxyl groups that have been found to be bound with a glucose unit of sugar in the plant tissue [13]. Phenolic compound are present in various form such as simple phenols (cinnamic acid and complex ones as Queinic that are inhibitors for microorganisms, but they are not toxic when found inside organisms because they are bound in the form of glycosate esters to give non-toxic compounds, but when aqueous hydrolysis occurs within the plant it is converted into phenolic compounds that are toxic and antibacterial, the plant phenols are divided into two parts:A) Preformed phenols that are naturally made by the plant B) Induced phenols are those produced by the plant in response to physical damage or pathogenic infections or when exposed to heavy metal salts or the effect of ultraviolet radiation or heat [15].

The new fields in algae research including what is concerned with the production of metabolic materials that is useful in various life fields. phenols are one of these materials in which there are multiple studies to separate them from plant sources. The algae and cyanobacterium are among the best and most important of these sources as they are produced after the acid decomposition of the extracts [16].

The importance of algae and its primary and secondary products have a bioactive activity that gave it an important characteristic in the pharmaceutical industry because it is antibacterial, anti-fungal, anti-parasitic, anti-algal. The materials produced from algae are either inside cells (Entracellular) or out cells (Extracellular) which have many uses especially anticancer one that blue-green algae (Oscillatoriaceae) had own it [17]. One of these important materials is polyphenols that show a wide biological range such as antioxidants because of benefit in reducing oxidation reactions [18], and it was mentioned, several algae contain these compounds [19]. Therefore, cyanobacteria extracts have biological activity and important role in the pharmaceutical industry [20], thus it considered a great source for naturally occurring compounds which have therapeutic and physiological effect and produced in small amounts as products from secondary metabolite processes [21].

\section{Materials and Methods}

\section{1 Growth and Maintenance of Cultures}

Oscillatoria sp. This microalgae is a cyanobacterium identified morphologically [22], [23], [24]. The thallus is a multicellular filamentous form, it was preserved and cultivated in modified Chu10 medium [25], [26], that consist of these components (g/L):

$\begin{array}{ll}\mathrm{Ca}\left(\mathrm{NO}_{3}\right) & 0.4 \\ \mathrm{~K}_{2} \mathrm{HPO}_{4} & 0.1 \\ \mathrm{NaCO}_{3} & 0.2 \\ \mathrm{MgSO}_{4} \cdot 7 \mathrm{H}_{2} \mathrm{O} & 0.25 \\ \mathrm{Na}_{2} \mathrm{SiO}_{3} & 0.25 \\ \text { Ferric Ammonium Citrate } & 0.05\end{array}$

The $\mathrm{pH}$ of the medium was adjusted to 7.7 and autoclaved at $121^{\circ} \mathrm{C}$ for $20 \mathrm{~min}$. This research was done at the Laboratory of Algal Research of Biology Department / Education for Pure Science College/ Mosul University. The cyanobacterium was grown in modified broth 
Chu10 medium inside simple photobioreactor that has supplied with air at $25 \pm 2{ }^{\circ} \mathrm{C}$ under photoperiod cycle 16:8 hour (Light: Dark) respectively see Figure 1.

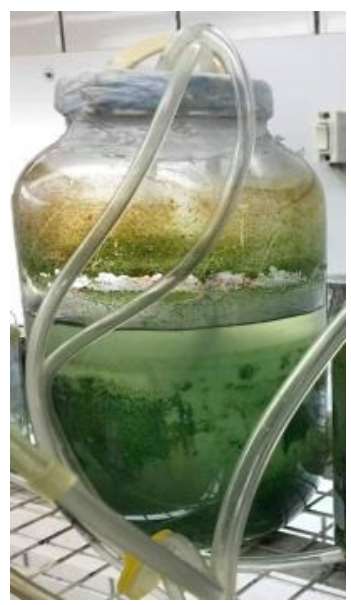

Fig. 1. Simple photobioreactor for cyanobacterium growth.

\subsection{Preparation of raw cyanobacterium extract}

The raw extract was prepared after collecting fresh weighted biomass of Oscillatoria by centrifugation (3000 rpm/15 min) after 14 days of inoculation and then drying it in the oven at $40^{\circ} \mathrm{C}$ for about 12 hours. Dried biomass $(5 \mathrm{~g})$ was taken and grinding by a ceramic mortar to make it fine powder, then ethanol $(95 \%)$ was added $(50 \mathrm{ml})$ to algal powder to make the raw ethanolic extract [27]. The mixture was well mixed and stored in the refrigerator overnight then filtered through Whatman No.1 filter paper under the vacuum.

\subsection{Extraction of phenolic compounds}

To extract the phenolic compounds of Oscillatoria from its raw ethanolic extract, the filtrated extract was concentrated under reduced pressure by using a rotary evaporator at respective boiling points of the solvent. The concentrated extract was kept in a closed container at $4{ }^{\circ} \mathrm{C}$ until another step of extraction done. Another step is an acidic degradation of the concentrated ethanolic extract [13], it was done by taking ( $2 \mathrm{ml}$ ) of that extract with adding (200 $\mathrm{ml}$ ) of hydrochloric acid $(2 \mathrm{M})$, then heating that mixture in a water bath $\left(90-100^{\circ} \mathrm{C}\right)$ for $30 \mathrm{~min}$ with stirrer followed by cooling the extract to room temperature. Next, the mixture was transferred into separating funnel and ethyl acetate $(100 \mathrm{ml})$ was added (this process is repeated twice), and two layers were observed: the top layer represents the ethyl portion containing free phenolic acids and it is concentrated using a rotary evaporator under pressure to obtain precipitate that was kept in $4^{\circ} \mathrm{C}$ until use in the diagnosis of phenols, whereas the bottom layer is the aqueous layer.

\subsection{Phenols Diagnosis by HPLC}

Phenolic compounds were dissolved in about $(1 \mathrm{ml})$ of methanol and filtered before analysis by $0.22 \mu \mathrm{m}$ Millipore filter and then analyzed by HPLC device that present in Environment and 
Water Department/Ministry of Science and Technology, SYKAM German type origin device see Fig. 2. with the following specifications used: Autosampler model: S5200, detector: V S2340, Pump model: S 2100 Quaternary Gradient, Column Oven model: S 4115 Pump, Column is $\mathrm{C}_{18}$-ODS (25 $\mathrm{cm}^{*} 4.6 \mathrm{~mm}$ ), Detector UV-360 $\mathrm{nm}$.

The chromatographic separation was carried out according to the method described by [28]. The separation process was carried by using a mixture of solvents A and B as a mobile phase and the flow rate was $1 \mathrm{ml} / \mathrm{min}$. Both solvents consisted of Methanol: D.W.: Acetic Acid but its different in that ratio on to another as this: Solvent A (85:13:2) and Solvent B (25:70:5) ml respectively. Many standards are used as phenols: Rutin, Quercetin, Apigenin, Luteolin, and Kaempferol.

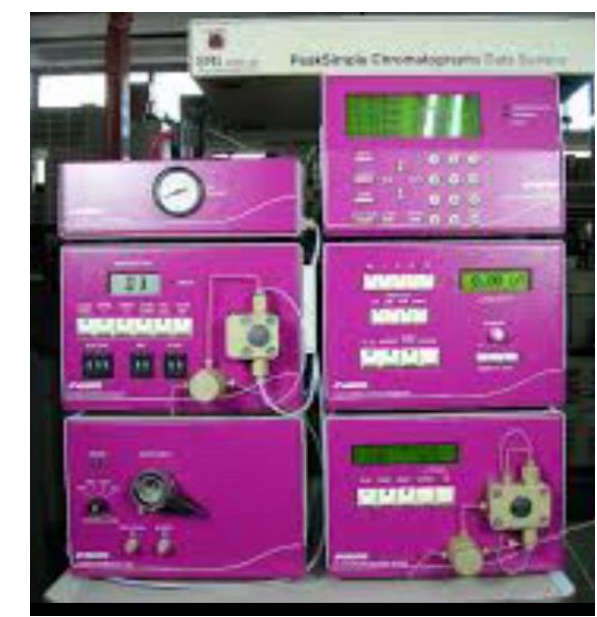

Fig. 2. Image of the HPLC device used to separate phenols.

\subsection{The antibacterial activity of crude and phenolic extracts}

Nutrient agar was prepared by dissolving $28 \mathrm{~g}$ from media powder in $1 \mathrm{~L} \mathrm{D.W}$. then autoclaving it at $121^{\circ} \mathrm{C}$ for $20 \mathrm{~min}$. Antibacterial activity of Oscillatoria sp. ethanolic raw extract and phenolic extract were performed by diffusion method [29]. The inhibitory effects of extracts were screened by placing $50 \mu \mathrm{l}$ of it in each agar well that plated with bacteria. The inoculated plates were incubated at $37^{\circ} \mathrm{C}$ for 24 hours, then results were taken by measuring the inhibition zone diameter $(\mathrm{mm})$ around the well $(6 \mathrm{~mm}$ by using stainless-steel borer) [30]. The extracts were screened against two Gram positive bacteria (Staphylococcus aureus and Bacillus subtitles) and two Gram negative bacteria (Pseudomonas aeroginosa and Escherichia coli).

\section{Results and Discussion}

\subsection{Cyanobacteria Growth and Maintenance}

After the growth of algae in a glass flask $(250 \mathrm{ml})$, inoculum $(10 \mathrm{ml})$ was taken for $100 \mathrm{ml}$ media in the simple photobioreactor. The medium was renewed every about 14 days, as well as 
making a temporary slide of the algae to ensure its purity and the appearance of pure thallus as shown in Figure 3.

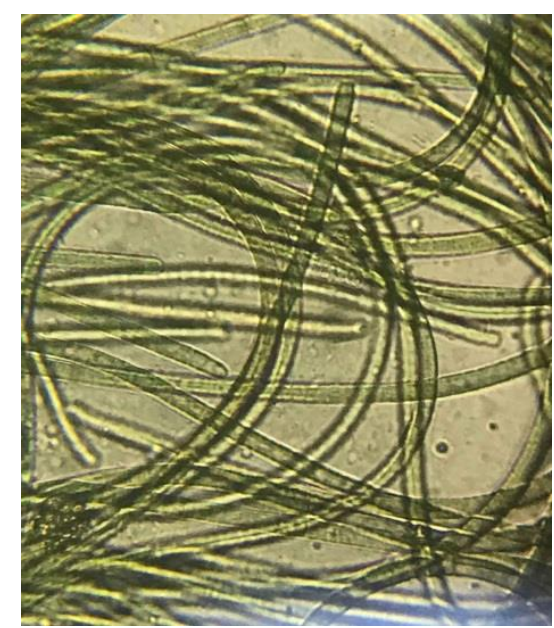

Fig. 3. Microscopic image of Oscillatoria thallus.

\subsection{Preparation of raw ethanolic and phenolic extracts}

After collecting and drying cyanobacterium biomass that subjected to grinding well, ethanolic alcohol (95\%) was added and shaken well overnight, the raw ethanolic extract was complete. The next step is to filter the extract to remove its residues and kept until using it at $4^{\circ} \mathrm{C}$ see Figure 4.

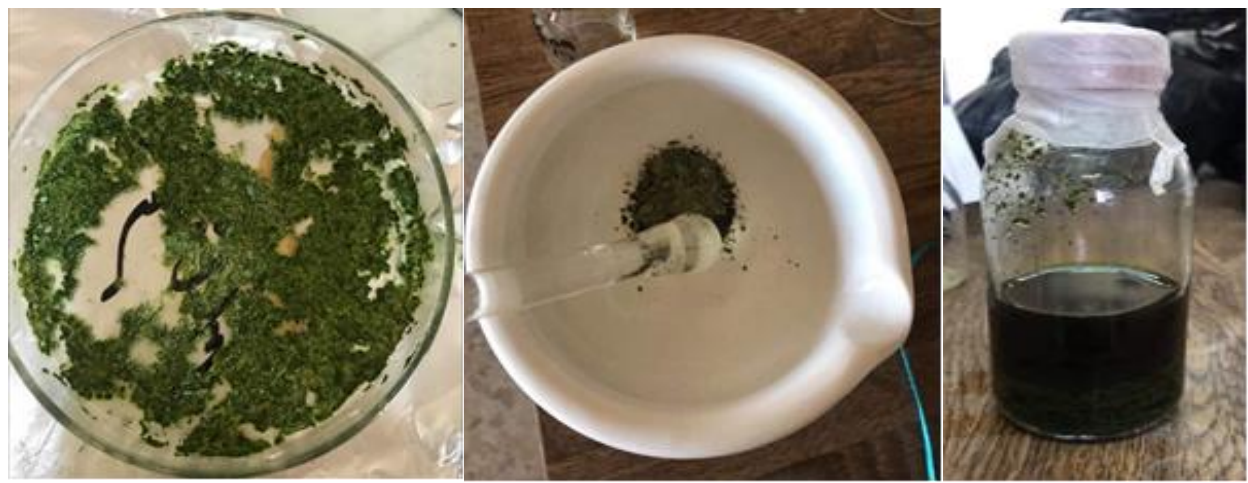

Fig. 4. The stages for preparing raw ethanolic extract.

After obtaining the raw ethanolic extract, it was concentrated by evaporation and complete the acid decomposition with transferred to separating funnel for the received phenolic extract from the upper layer after ethyl acetate addition, see Figure 5. 


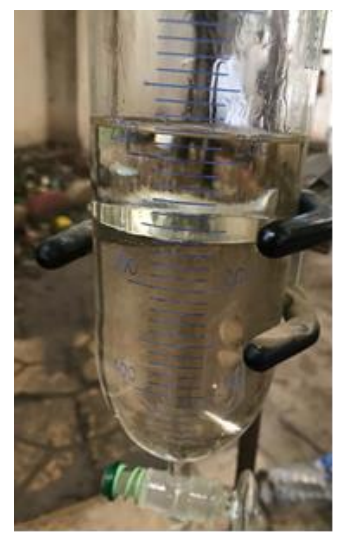

Fig. 5. Separation of phenolic extract in a separation funnel.

The phenols with the upper layer concentrated by rotary evaporation as shown in Figure 6.

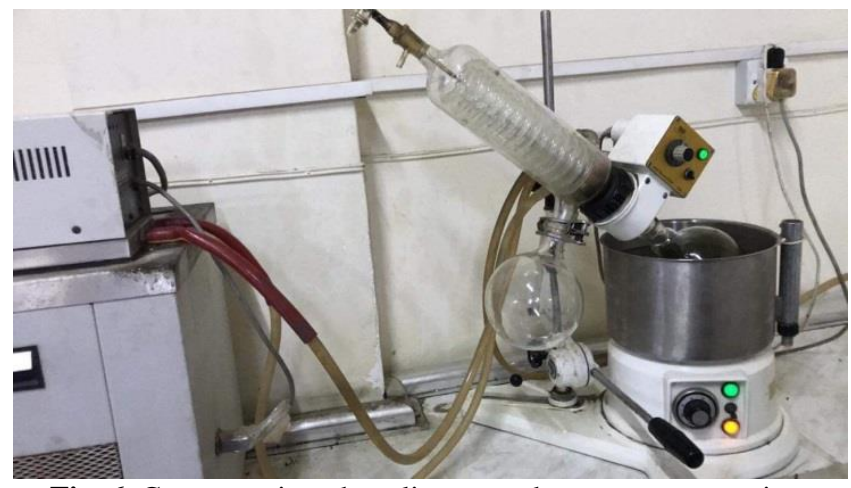

Fig. 6. Concentrating phenolic extract by rotary evaporation.

At last, phenolic compounds of phenolic Oscillatoria extract (approximately $2 \mathrm{ml}$ ) transferred to an airtight container.

\subsection{Diagnosis of Oscillatoria phenols in HPLC}

The types of phenols present in the extract of Oscillatoria sp. was identified using the HPLC device by compared with the data of the standard phenolic samples, the types were diagnosed and their percentages were determined in the extract as shown in Table 1. and Figure 7.

Table 1. HPLC data for standard phenols and phenols in the cyanobacterial sample.

\begin{tabular}{|l|c|c|c|c|}
\hline No. & $\begin{array}{c}\text { Phenolic } \\
\text { Compound }\end{array}$ & $\begin{array}{l}\text { Standard Retention } \\
\text { Time }(\mathrm{min})\end{array}$ & $\begin{array}{c}\text { Sample retention } \\
\text { time }(\mathrm{min})\end{array}$ & $\begin{array}{c}\% \text { of area in } \\
\text { the sample }\end{array}$ \\
\hline 1 & Apigenin & 3.06 & 3.40 & 11.5 \\
\hline 2 & Kaempferol & 3.79 & 3.86 & 5.2 \\
\hline 3 & Rutin & 4.84 & 4.69 & 44.4 \\
\hline 4 & Luteolin & 5.18 & 5.15 & 9.4 \\
\hline 5 & Quercetin & 6.56 & 6.05 & 11.8 \\
\hline
\end{tabular}


The results in Table 1. and Figure 7. shows the presence of several types of phenolic compounds in Oscillatoria algae extract in varying proportions and the highest of which was for Rutin compound (44.4\%), followed by similar proportions Quercetin and Apigenin compounds with rates of 11.8 and $11.5 \%$ respectively and Luteolin compound $9.4 \%$ and Kaempferol the lowest in $5.2 \%$.

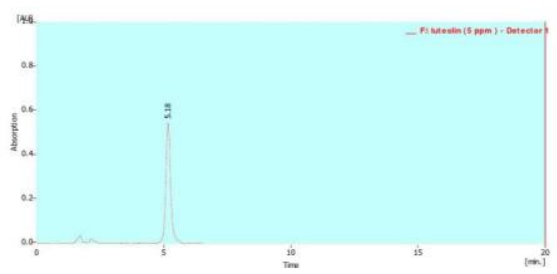

Luteolin

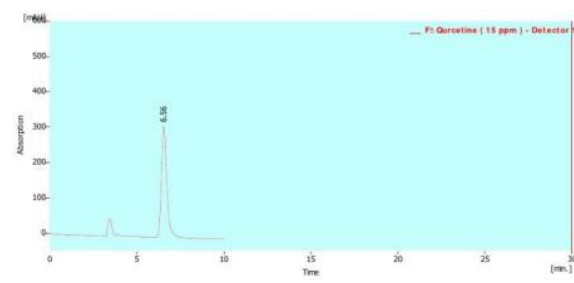

Quercetin

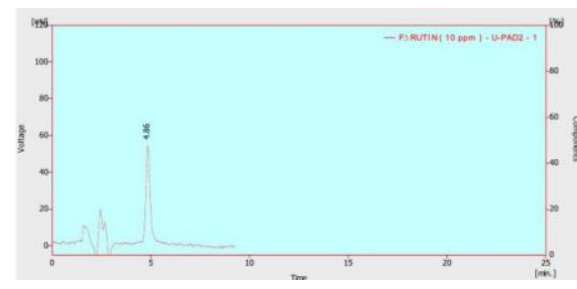

Rutin

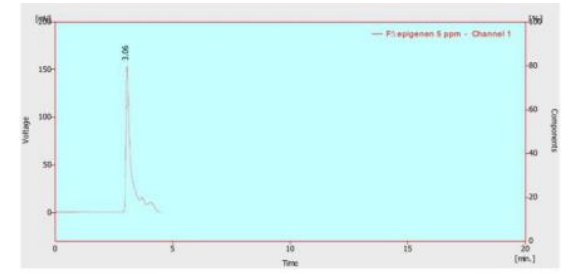

Apigenin

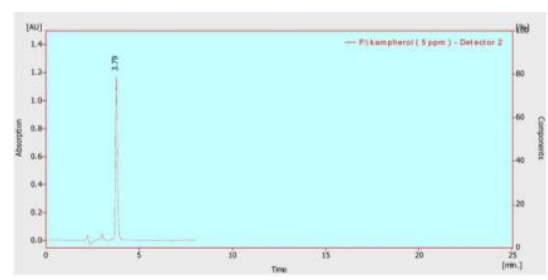

Kaempferol

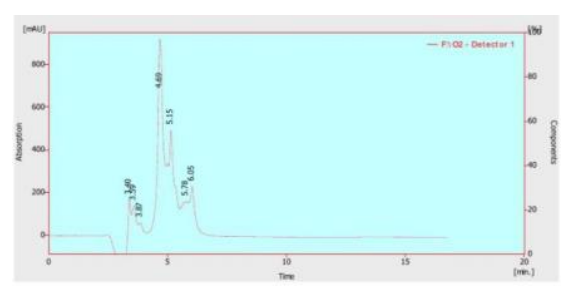

Oscillatoria phenols

Fig. 7. Measurements of HPLC phenolic compounds.

Each phenolic compound has special protective importance. Rutin is the most common in plants and has a protective function from the sun in addition to many uses including anti-oxidant and anti-inflammatory and vasodilating action as well as lowering blood sugar [31]. Quercetin is a simple phenol and is found in tea, onions and citrus fruits and are used in the manufacture of many drugs such as Estrogens, Digoxin, Cisplatin, Fellodipine and others as it works as an antioxidant and catalyst for some biological pathways and inhibitor of several enzymes [32]. Apigenin found in many plants; it is a class of glycosides, which is a natural Flavon having a yellow substance and used to dye wool [33]. It also has protective properties from chemicals that cause cancer, inhibiting the spread of cancer cells to other tissues and preventing the growth of the tumor and reducing free radicals and removing harmful toxins from the body, while 
Luteolin is available in boiled chamomile, celery, and pepper and is considered an anti-cancer flavonoid and protects the liver and lung tissues from cancer and helps to detoxify the body toxins, Apigenin and Luteolin are found in low concentrations in foods but have great effects in preventing the spread of cancer cells. Kaempferol is also a flavonoid and has anti-oxidant and anti-bacterial properties in addition to its anti-cancer activity and is found in several plants [34].

As a result of this study, the presence of many phenols in the cyanobacterium extract agrees with the possibility of adopting cyanobacteria as a new and rich source for these compounds [35]. Also, in many studies conducted on brown algae, the presence of many phenols in the form of accumulated phlorotannins has published and it has a unique composition that is not found in terrestrial plants and that it constitutes about $25 \%$ of the fresh weight of brown algae, and that its concentration varies with the habitat, harvest time, the exposed light density, and the available nutrients [36], [37], while [19] indicated that phenolic content in algae products depends on the different extraction conditions used in terms of the type of solvent used for aqueous extraction, methanol, chloroform, ethanol, hexane, ethyl acetate extracts.

Table 2. Effect of ethanol and phenolic extracts on pathogenic bacteria

\begin{tabular}{|c|c|c|}
\hline \multirow[t]{2}{*}{ Pathogenic Bacteria } & \multicolumn{2}{|c|}{$\begin{array}{l}\text { Pathogenic bacteria inhibition diameter } \\
(\mathrm{mm}) / \text { rate of } 3 \text { replicates }\end{array}$} \\
\hline & \begin{tabular}{l}
\multicolumn{2}{c}{ Sample } \\
control raw \\
extract \\
\end{tabular} & $\begin{array}{l}\text { Phenolic } \\
\text { extract }\end{array}$ \\
\hline $\begin{array}{l}\mathrm{G}+\text { bacteria } \\
\text { Staphylococcus aureus } \\
\text { Bacillus subtillus }\end{array}$ & - & $\begin{array}{l}* 20 \\
19\end{array}$ \\
\hline $\begin{array}{l}\mathrm{G} \text { - bacteria } \\
\text { Psedomonas aeroginosa } \\
\text { Escherichia coli }\end{array}$ & - & $\begin{array}{l}10 \\
16 \\
\end{array}$ \\
\hline
\end{tabular}

*Pathogenic bacteria inhibition diameter $(\mathrm{mm}) /$ rate of 3 replicates

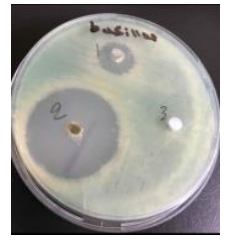

$B$.

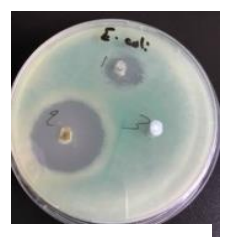

E. coli

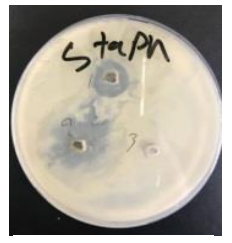

Staph.

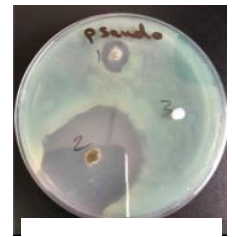

Psudo.

Fig. 8. Pictures of the pathogenic antibacterial activity 
Antibacterial activity of the crude and phenolic extracts of the cyanobacterium: The efficacy of inhibition of crude and phenolic extracts of Oscillatoria was shown in Table 2. and Figure 8. The phenolic extract showed a great inhibitory effect on the Gram-positive bacteria than its effect on the negative bacteria. This is consistent with many studies, and the biggest effect was on Staphylococcus aureus $(\mathrm{G}+)$ in which the inhibition diameter was $(20 \mathrm{~mm})$ and the least effect on the negative bacteria (G-) Pseudomonas aeroginosa with an inhibition diameter $(10 \mathrm{~mm})$. It has been suggested that the cause is the resistance of negative bacteria that due to the very low permeability of their outer membrane equipped with secondary resistance mechanisms such as having anti-flow pumps [38]as well as, the cell membrane layer has a component of phospholipids which is impermeable to many compounds [39].

\section{Conclusions}

Oscillatoria sp. ethanolic extract was screened for phenolic content and seem to have potency as a rich source of these compounds. In HPLC analysis, many types of phenols were diagnosed such as Rutin, Quercetin, Apigenin, Luteolin, and Kaempferol. Phenols of cyanobacterium Oscillatoria have antibacterial activity against both Gram positive and Gram negative bacteria that make it a good choice to use it with antibiotics materials in the future. The cyanobacterium growth in simple photobioreactors is a perfect method to get algal biomass for using it in these kinds of researches. Thus, Further work must be carried out to determine the optimal conditions for producing phenols from algae with trying to increase that production. Although, obtaining and diagnosis of more phenols with the study of their synergistic effect with antibiotics affecting bacteria and applying it with animals later.

\section{Acknowledgment}

Authors are grateful to the Department of Biology/ Education for Pure Science College/ Mosul University/ / Ministry of Higher Education and Scientific Research, MOSUL, IRAQ, and Ministry of Science and Technology/Environment and Water Department, Baghdad, IRAQ, for supporting this study with HPLC data.

\section{References}

[1] Harmsen, P.: Microalgae the green gold of the futures Large Scale Sustainable Cultivation of microalgae for the production of bulk commodities: Print prepress, Wagering. UR. ISBN 978-94-6173062-6. www.algae.wur.nl. (2011)

[2] Khafaji, Z. M.: Microbial Biotechnology (Molecular Guidance). Genetic Engineering Institute for Biotechnology for Postgraduate Studies. University of Baghdad - Iraq (2008)

[3] Frost, P., Schinder; P., Porter-Goff, E., Middleton, C.: The Kawrtha lakes: Their place in the ecosystem, when they become a hazard and what controls their growth: 37(2012)

[4] Barsanti, L., Gualtiers, P.: Algae Anatomy, Biochemistry and Biotechnology. Taylor and Francis Group. LLC. CRC press. (2006)

[5] Pignolet, O., Jubeau, S., Vaca- Garcia, C., Michaud, P.: Highly valuable microalgae: biochemical and topological aspects. Journal of Industrial Microbiology and Biotechnology, 40(8): 781-796 (2013)

[6] Chakdar. H., Pabbi, S.: Extraction and purification of phycoerythrin from Anabaena varibilis (CCC421), Phykos, 42(1): 25-31(2012)

[7] Safafar, H., Van Wagenen, J., Moller, P., Jacobsen, C. Carotenoids.: phenolic compounds and tocopherols contribute to the antioxidant properties of some microalgae spiecies grown on industrial wastewater. Marine Drugs,13,7339-7356 (2015) 
[8] Abd- EL-Aty, A. M., Mohamed, A. A.: In vitro antioxidant and antibacterial activities of two fresh water cyanobacterial species, Oscillatoria and Anabaena sphaerica. Journal of Applied Pharmaceutical science, vol.4(07), pp.069-075(2014)

[9] Graham, L.E., Wilcox, L. W. Algae. prentrce- Hal, Inc. USA (2000)

[10] Vashishta, B.R., Sinha, A.K., Singh, V.P.: Botany for Degree Students Algae S. CHAND Higher Academic. Printed on Gnvironmental Friendly ECF paper. S. Chand Qublishing S. CHAND and Company LTD (2012)

[11] Ragland, A., Kumaresan, V., Arumugam, N.: A Text Book of Botany. Volume- I. Algae, fungi, Bryophytes, Microbiology \&p; ant Pathology. First Edition SARAS Publication, Nagercoil. India. (2015)

[12] Khoddami, A., Wilkes, M. A., Roberts. T.H.: Techniques for analysis of plant Phenolic compounds Molecules, 18(2): 2328-75 (2013)

[13] Harborn, J. B. Phytochemical Methods: A guid to Modern Teachique of plant Analysis. 1st ed. Cox and Wymwn . London, P. 52-73 (1973)

[14] Ollestram, O., Lavsson, S.: Salicylic acid mediates resistance in the willow salix Viminals againtes Gall Midge Dasineura. (2003)

[15] Vincenzo, L., Veronica, M., Lattanzio, T., Angila, C.: Role of phenolics in the resistance mechanisms of plant against fungal pathogen and insects. Research sign post 37-66 (2), fort P.O., Trivandrum- 69523, Kerala, India. (2006)

[16] Teixeira, J., Gasper, A., GArrido, E. M., Garrido, J., Borges, F.: Hydroxyl- cinnamic acid antioxidant: an electrochemical overview. Biomed Research International, 11 (2013)

[17] Thummajitsakul, S., Silprasit ,K., Sittipraneed , S.: Antibacterial activity of crude extracts of cyano bacteria phormidium and microcoleus spiecse. African Journal of Microbiology Research, v.6 (10) : 25742579 (2012)

[18] Freile- Pelegrin, Y., Robledo, D.: Biaactive Phenolic compounds from algae. Chapter 6 from Bioactive Compounds from Marine foods. Ed. Blanca Hernandez- Ledesma and Miguel Herero. John Wiley \& Sons, Ltd. Published (2014)

[19] Machu, L., Misurcova, L., Ambrozova, J., Orsavova, J., Mlcek, J., Sochor, J., Jurikova, T.: Phenolic Content and antioxidant Capacity in algal food products. Molecules, 20, 1118-1133 (2015)

[20] Kwei, C. K.: Elucidation and isolation of specific bioactive compounds in Cyanobacteria isolates. Doctor thesis. The university of Adelaide. Australia (2012)

[21] Zorica, S., Dragana, C., Jelica, S., Maja, K., Dejan, S.: Antibacterial, anti-fungal and cytotoxic activity of terrestrial Cyanobacterial Strains from Serbia. Science in China Series 51(10): 941-947 (2008)

[22] Desikachary, T. V.: Cyanophyta. Indian Council Agricultural Research. New Delhi. India (1959)

[23] Prescott G. W.: Algae of the westeren great lake area. $6^{\text {th }}$ ed. Willam C. Brown Co. Publisher Dubugue. Towa (1975)

[24] Wehr, J. D., Sheath, R. G.: Freshwater Algae of North America. Ecology and Classification. ACADEMIC PRESS. Elsvier Science (USA) (2003)

[25] Al-Mousawi, A.: HAbiological studies on algaein rice-field soil prom tee Iraqi marshes. Durham theses, Durham University Available at Durham E-Theses. Online: http//etheses.dur.ac.uk/7134 (1984)

[26] Al-Katib, M., Al-Shahri, Y., Al-Niemi, A.: Biosynthesis of silver nanoparticles by cyanobacterium Gloeocapsa. International Journal of Enhanced Research in Science, Technology, Engineering, vol 4, September.ISSN:2319-7463 (2015)

[27] Grand, A., Wondergem, P. A., Verpoorte, R., Pousset, J. L.: Anti-infections Phytotherpies of the treeSavannah of Senegal (West-Africa) II- Antimicrobial Activity of 33 Species. J. Erthnopharm, 22(1): 25311 (1988)

[28] Mradu, G, Saumyakanti, S., Sohini, M., Arup, A.: HPLC profiles of standerrd Phenolic Compounds present in Medicinal Plants. International Journal of Pharmacognosy and Photochemical Research, 4(3): $162-167$ (2012)

[29] Perez, C., Poaul, M., Bazaerque, P.: An antibiotic assay by the agar well diffusion method. Acta. Boil. Med. Exp., v15: 113-115 (1990)

[30] Vandepitte, J., Engback, K., Piot, P., Heuk, C.: Basic Laboratory Procedures in Clinical Bacteriology, word Health Organization, Geneva (1991) 
[31] Al-Dhabi, N. A., Arasu, M.V., Park, C.H., Park, S.U.: An up to date review of rut in and its biological and Pharmacological activities, Exclio. J., (14): 59-63(2015)

[32] Lakhanpal, P., Rai, D. K.: Quercetin A versatile flavonoid, Internet Journal Update, V. (2): 22-37 (2007)

[33] Wikipedia. Org, http://en. wikipedia. org/wiki/microphyte.

[34] Garde. C., T.: Gonzalo- diag, A. Keampherol biosynthesis and food source and therapeutic uses. Nova Sc. Publishers, Inc. New York (2016)

[35] Xue, Y., He, Q.: Cyanobacteria as cell factories to produce plant secondary metabolities. Front. Bioeng. Biotechnol. , 3:57 www.forntiers.org (2015).

[36] Ragan, M. A., Glombitza, K. W.: Phlorotannins, brown algal polyphends IN.: Progress in Phycological Research, Biopress Ltd.: Bristol, Uk.: 129-241 (1986)

[37] Targett, N. M., Arnold, T.M.: Predicting on marine hervibores in tropical and temperate Ocean Journal of Phycologys 34: 195-206 (1998)

[38] Goering, R.V., Dochrell, H.M., Wakelin, D., Zuckerman, M., Chiodini, P. L., Rott, I.M.: Mims, C. Mims Medical Microbilogy 4th ed. Mosby. Elsevier Ltd. China (2008)

[39] Cowan, M.M. Plant products as out microbial agents. J. Clinical Biology America Society for Microbiology, Miami University. Oxford. Ohio, 12(4): 564-582 (1999) 